\title{
Synthesis and Antibacterial Activity of Novel 3-Hydroxy Benzoic Acid Hybrid Derivative [Part I]
}

\author{
Maruti S. Satpute ${ }^{1}$, Vijay D. Gangan ${ }^{1}$, Indu Shastri ${ }^{3 *}$ \\ ${ }^{1}$ Department of Chemistry, R. D. National College and W. A. Science College, Linking Road, Bandra (W), \\ Mumbai, Maharashtra, India \\ 2Department of Chemistry, Loba R \& D Centre, Loba Chemie Pvt. Ltd., Plot No. D - 22, Tarapur MIDC, Boisar, \\ Palghar, Maharashtra, India \\ ${ }^{3}$ Department of Chemistry, R. D. National College and W. A. Science College, Linking Road, Bandra (W), \\ Mumbai, Maharashtra, India
}

\begin{abstract}
3-hydroxy benzoic acid is an organic chemical which can be obtained naturally as well as synthetically. The literature survey reveals its various biological properties viz. antimicrobial, antialgal, antimutagenic, antiestrogenic, hypoglycemic, anti-inflammatory, anti-platelet aggregating, nematicidal, antiviral, antioxidant etc. It is also reported to be used as preservative in many drugs, cosmetic products, pharmaceuticals, food and beverages. Some derivatives of 3-hydroxybenzoic acid are found to possess direct action on Hbs molecules, inhibit acetic acid induced oedema and used in management of sickle cell disease. It is also has wide applications in perfumery industries. In this paper, novel ester / hybrid derivative of 3- Hydroxy benzoic acid was synthesized and tested for its potential antibacterial activity. This combinatorial synthesis of novel 3Hydroxy benzoic ester / hybrid derivative can be a useful approach to generate potent chemotherapeutic agents in developing new drug candidates.
\end{abstract}

Keywords : 3-Hydroxy Benzoic Acid, IR, 'HNMR, TOF MS, DCC, DMAP, Biological Activities Antibacterial, Ditch-Plate Method.

\section{INTRODUCTION}

Phenolic compounds exist in most plant tissues as secondary metabolites, i.e. they are not essential for growth, development or reproduction but may play roles as antioxidants and in interactions between the plant and its biological environment. Phenolics are also important components of the human diet due to their potential antioxidant activity ${ }^{1}$, their capacity to diminish oxidative stress induced tissue damage resulted from chronic diseases ${ }^{2}$, and their potentially important properties such as anticancer activities ${ }^{3-5}$. 3-Hydroxybenzoic acid is found in common plants such as grapefruit (Citrus paradisi), olive oil (Olea europaea) ${ }^{6}$, and medlar fruit (Mespilus germanica) ${ }^{7}$. It has glucosylating activity ${ }^{8}$. 3-Hydroxy benzoic acid is a naturally occurring active compound ${ }^{9}$ having antimicrobial, anti-inflammatory and antioxidant / anticancer properties, in continuation ${ }^{10-13}$ to our earlier work we thought of synthesizing compounds with novel ether, ester and hybrid derivatives of 3hydroxy benzoic acid wherein 3-hydroxy benzoic acid would be etherified, esterified and hybridized with various other compounds and to check whether these compounds possess above biological activities. The objective of this study is to condense two 
molecules of the same disease domain to produce more potent candidate in the same disease domain or to condense two molecules of different disease domain to produce mixed variety of those disease domain or to have drug candidate with entirely different biological activity.

\section{METHODS AND MATERIAL}

Materials : Chemicals used were of a laboratory grade. The reactions were monitored by TLC on aluminium-backed silica plate visualized by UV-light.

\section{EXPERIMENTAL}

Melting points were determined on a Thomas Hoover capillary melting point apparatus using digital thermometer. IR spectra were recorded on a Shimadzu FTIR Prestige model as $\mathrm{KBr}$ pellet. ${ }^{1} \mathrm{H}$ NMR spectra were recorded on a Varian $200 \mathrm{MHz}$ spectrometer in $\mathrm{CDCl}_{3}$. Chemical shifts were recorded in parts per million down field from tetramethyl silane. Mass spectra were recorded on a TOF MS ES mass spectrometer. Elemental analysis were carried out as a percentage on a Thermo finnigan, Flash EA 1112 series, Italy.

\section{RESULTS AND DISCUSSION}

Preparation of 3-methoxy benzoic acid :- 3-hydroxy benzoic acid (1) was subjected to esterification using ( $\mathrm{MeOH} /$ Conc. $\mathrm{H}_{2} \mathrm{SO}_{4}, 8$ hrs.) to yield 3-hydroxy methyl benzoate (2) which was subjected to etherification $\left(\mathrm{K}_{2} \mathrm{CO}_{3} /\right.$ Acetone /dimethyl sulphate) to yield 3-methoxy methyl benzoate (3) which was purified by column chromatography. This purified ether derivative was subjected to hydrolysis using $10 \%$ Aq. $\mathrm{KOH}$ in $\mathrm{MeOH}$ followed by precipitation with dil. $\mathrm{HCl}$ at $10-15^{\circ} \mathrm{C}$ to yield off white ppt. of 3methoxy benzoic acid (4) quantitatively. It was filtered through Buchner funnel, suck dry and finally dried in oven at $70^{\circ} \mathrm{C}$ for $12 \mathrm{hrs}$.

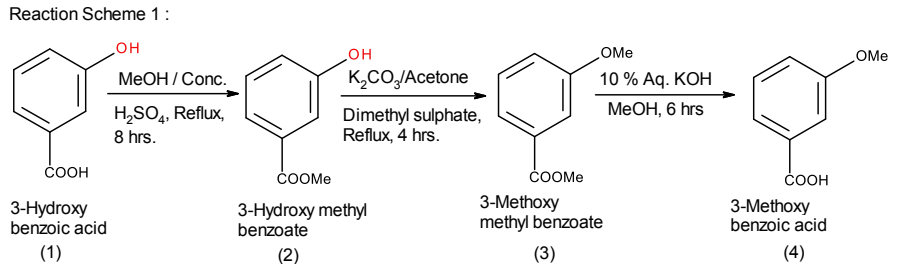

Above 3-Methoxy benzoic acid was then condensed with 3-Hydroxy methyl benzoate under DCC / DMAP / Pyridine condition in dichloromethane to yield desired hybrid derivative whose structure was unambiguously confirmed by IR, ${ }^{1} \mathrm{H}$ NMR, Mass spectroscopy and elemental analysis and tested for their potential antimicrobial activity.

Synthesis of Fused Molecules using compound(5):This was prepared by following general method as depicted below.

To a stirred solution of 3-Hydroxy methyl benzoate [A] (1 eq.) in $30 \mathrm{ml}$ dichloromethane was added DCC [C] (1.3 eq.), DMAP [D] (0.05 eq.), pyridine [E] (0.5 eq.) and the reaction mixture stirred at room temperature for $5 \mathrm{~min}$. Clear solution of reaction mixture was obtained. To this, compound [B] aromatic / substituted aromatic acid (1.3 eq.) was added and stirring continued at room temperature for next $24 \mathrm{hrs}$. As the reaction proceeds, urea derivative precipitates out as by product. The progress of the reaction was monitored by TLC for completion of reaction.

Work up :-The reaction mixture filtered through celite bed which get rids of by product urea derivative. The filtrate was concentrated to minimum, preadsorbed on silica gel (100 - 200 mesh) and purified by column chromatography with increase in concentration of ethyl acetate in petroleum ether. The general yields of this reactions ranges between $70-80 \%$. This is another method of preparing esters and follows green chemistry parameters. 
The most significant features of this methodology are (a) good accessibility of the reagent and its stability (b) a stoichiometric amount of reagent can be used by direct weighing, avoiding excess (c) no evolution of hazardous vapors during the reaction (d) the total elimination of the use of toxic organic solvents (e) a simple experimental procedure (g) good control over the outcome of the reaction by varying the amount of reagent (h) less expensive. The aforesaid protocol thus provides an improved procedure for the synthesis of useful hybrid derivatives having important pharmaceutical, agricultural and other physicochemical properties.

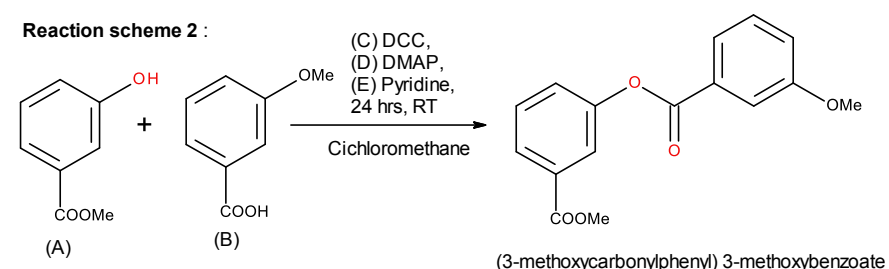
(5)

\section{Probable mechanism for fused / hybrid molecules}

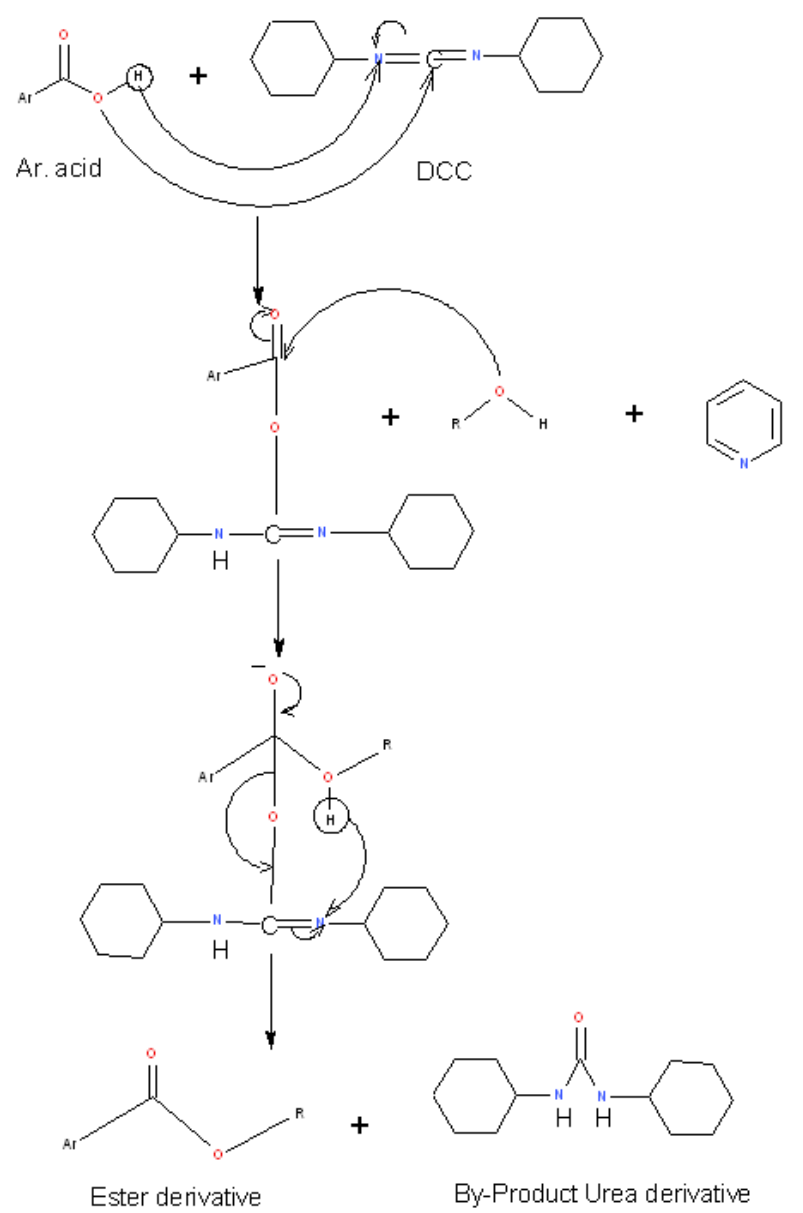

Characterization of compounds (4) and (5) :

3-Methoxy benzoic acid (4) :-

${ }^{1} \mathrm{H} \mathrm{NMR}\left(\mathrm{CDCl}_{3}, 200 \mathrm{MHz}\right) \delta \mathrm{ppm}: 3.89$ $\left(\mathrm{s}, 3 \mathrm{H}, 1 \mathrm{x} \mathrm{Ar}-\mathrm{OCH}_{3}\right), 7.1-7.8(\mathrm{~m}, 4 \mathrm{H}$, $\mathrm{ArH})$; IR (KBr) cm ${ }^{-1}:-2960,2872,2829$ (Methyl, methines), $2670-2628$ (-OH stretching of $-\mathrm{COOH}$ group), 1681 (acid carbonyl >C=O), $1603-1582$ (aromatic); TOF MS ES: $175(\mathrm{M}+\mathrm{Na})$; Molecular Formula $\mathrm{C}_{8} \mathrm{H}_{8} \mathrm{O}_{3}$; Melting range 80 $82^{\circ} \mathrm{C}$; Elemental Analysis, Calcd.: C $63.20 \%$, H $5.30 \%$, O $31.50 \%$. Found C $63.18 \%$, H $5.32 \%$, O $31.49 \%$;

(3-methoxycarbonylphenyl) 3-methoxybenzoate (5) :-

${ }^{1} \mathrm{H} \mathrm{NMR}\left(\mathrm{CDCl}_{3}, 200 \mathrm{MHz}\right) \delta \mathrm{ppm}: 3.87$ $\left(\mathrm{s}, 3 \mathrm{H}, 1 \mathrm{x} \mathrm{Ar}-\mathrm{OCH}_{3}\right), 3.89(\mathrm{~s}, 3 \mathrm{H}, 1 \mathrm{x}$ $\left.\mathrm{Ar}-\mathrm{OCH}_{3}\right), 7.0-8.0(\mathrm{~m}, 8 \mathrm{H}, \mathrm{ArH}) ; \mathrm{IR}$ (KBr) cm-1:- 2964, 2905, 2870 (Methyl, methines), $2670-2628$ (-OH stretching of $-\mathrm{COOH}$ group), 1725 \& 1685 (ester carbonyl >C=O), 1615 - 1602 (aromatic); TOF MS ES: $175(\mathrm{M}+\mathrm{Na})$; Molecular Formula $\mathrm{C}_{16} \mathrm{H}_{14} \mathrm{O}_{3}$; Melting range 86 $90^{\circ} \mathrm{C}$; Elemental Analysis, Calcd.: C $67.10 \%, \mathrm{H} 4.90 \%$, O $28.0 \%$. Found C $67.12 \%, \mathrm{H} 4.88 \%$, O $27.98 \%$;

\section{CHOROMATOGRAPHIC SYSTEM}

Column chromatography : For column chromatography 100 - 200 mesh Acme grade silica gel is used. The crude reaction mixture is concentrated under reduced pressure to yield crude mass which is preadsorbed on silica gel and purified by column chromatography with increase in concentration of Ethyl acetate in Petroleum ether. The fractions having similar ' $r f$ ' values were pooled together, concentrated and subjected for 
characterization using various spectroscopic techniques.

Thin layer chromatography : TLC plates were prepared using silica gel G (ACME, BOMBAY). Pet. ether: EtOAc ( $85: 15)$ was used as the solvent system. Radial chromatography : The circular glass plates of thickness $1 \mathrm{~mm}$, were prepared by using silica gel (PF254, E. MERCK, $50 \mathrm{~g}$ ) in cold distilled water (105 $\mathrm{ml})$. For elution, gradually increasing concentrations of EtOAc in pet ether were employed.

\section{BIOLOGICAL ACTIVITY}

Antibacterial Activity using ditch plate method ${ }^{14}$ :-

The synthesized molecules were screened for their antibacterial activity at $100 \mu \mathrm{g} / \mathrm{ml}$ concentration using ditch plate method against Gram + ve (Staphylococcus aureus) and Gram negative (Escherichia coli) bacterial species quantitatively. The results of the antibacterial activities are summarized in Table 1.

Theory : Ditch plate method is the method of chosen to test the anti-bacterial activity of compounds. It is a preliminary method to screen the anti-microbial potential of compounds / drugs, which are insoluble or partially soluble in aqueous phase. In this method, the test compound is seeded in an agar plate and the test organisms are streaked across to test the inhibition of the growth as a marker of antimicrobial activity.

PROCEDURE : A ditch $(10 \mathrm{~mm} \times 70 \mathrm{~mm})$ is cut into sterile $\mathrm{MH}$ agar plate. The test drug / compound is added to $5 \mathrm{ml}$ molten $\mathrm{MH}$ agar butt at $40^{\circ} \mathrm{C}$ and this mixture is poured into the ditch and allowed to solidify. The ditch should be made in level with the rest of the agar by pouring the mixture. The different bacterial cultures are streaked perpendicular to the ditch using nichrome wire loop. The plate is then incubated at $37^{\circ} \mathrm{C}$ for 24 hours. The results are observed as inhibition of bacterial growth on the ditch as well as adjacent to the ditch.

Table 1 : Antibacterial Activity Results

Antibacterial activity of compound (5) on Escherichia coli [Gram negative]

\begin{tabular}{|c|c|c|c|c|}
\hline \multirow{2}{*}{ Sr. No. } & \multirow{2}{*}{$\begin{array}{l}\text { Name of the } \\
\text { compound }\end{array}$} & \multicolumn{3}{|c|}{$\begin{array}{l}\text { Zone of inhibition (in } \\
\mathrm{mm} \text { ) }\end{array}$} \\
\hline & & 1 & 2 & Mean \\
\hline 1 & $\begin{array}{l}\text { 3-Hydroxy } \\
\text { methyl } \\
\text { benzoate }(2)\end{array}$ & $14 \mathrm{~mm}$ & $\begin{array}{c}18 \\
\mathrm{~mm}\end{array}$ & $16 \mathrm{~mm}$ \\
\hline 2 & $\begin{array}{c}\text { (3- } \\
\text { methoxycarbon } \\
\text { ylphenyl) 3- } \\
\text { methoxybenzo } \\
\text { ate (5) }\end{array}$ & $35 \mathrm{~mm}$ & $\begin{array}{c}34 \\
\mathrm{~mm}\end{array}$ & $\begin{array}{l}34.5 \\
\mathrm{~mm}\end{array}$ \\
\hline
\end{tabular}

Antibacterial activity of compound (5) on Staphylococcus aureus [Gram positive]

\begin{tabular}{|c|c|c|c|c|}
\hline \multirow{2}{*}{ Sr. No. } & \multirow{2}{*}{$\begin{array}{c}\text { Name of the } \\
\text { compound }\end{array}$} & \multicolumn{3}{|c|}{ Zone of inhibition (in mm) } \\
\cline { 3 - 5 } & $\begin{array}{c}\text { 3-Hydroxy } \\
\text { methyl } \\
\text { benzoate (2) }\end{array}$ & $18 \mathrm{~mm}$ & 16 & $17 \mathrm{~mm}$ \\
$\mathrm{~mm}$ & 2 & Mean \\
\hline 2 & $\begin{array}{c}(3- \\
\text { methoxycar } \\
\text { bonylphenyl } \\
\text { ) 3- } \\
\text { methoxyben } \\
\text { zoate (5) }\end{array}$ & $31 \mathrm{~mm}$ & 30 & 30.5 \\
$\mathrm{~mm}$ & $\mathrm{~mm}$ \\
\hline
\end{tabular}



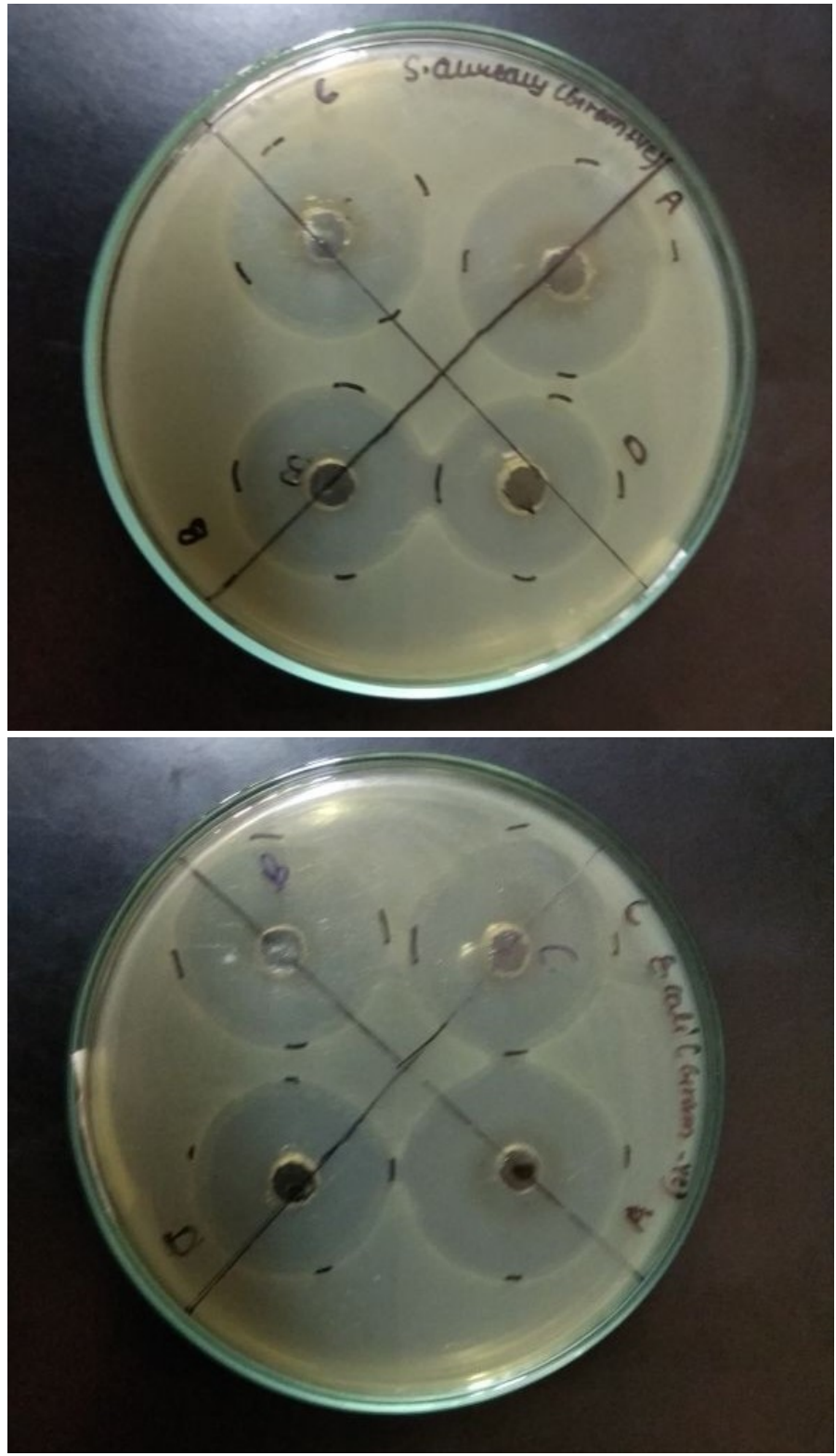

IV.CONCLUSION

The novel hybrid derivative of 3-Hydroxy benzoic acid was synthesized by cost effective industry viable process following the principle of green chemistry. The synthesis of hybrid derivative is another way to prepare ester derivatives using DCC as dehydrating agent in a reasonably good yield. The probable mechanism for the formation of hybrid derivative was also discussed.

The biological activity suggest that the base molecule 3-hydroxy methyl benzoate have anti-bacterial activity against both the bacterial cultures. Its derivatives viz. 5 was also active against both Gram + ve and Gram - ve cultures. Thus, fused molecules of 3-Hydroxy benzoic acid (5) having alkyl side chain was potential antibacterial candidate. In depth analysis of these compounds through structure activity relationship studies would provide further insight and can be an interesting topic of future studies.

The structural diversity and the pronounced biological activities encountered in the 3-hydroxy benzoic acid derivative suggests that this class of compounds is worthy for further studies that may lead to derivatives by using combinatorial chemistry approach is an alternative strategy to new therapeutic discovery. In other words the generation of diverse 3hydroxy benzoic acid derivatives develops new therapeutic molecules that might result in candidates having better activity.

The synthesized hybrid derivative was chemically new and confirmed by Scifinder search.

\section{ACKNOWLEDGEMENT}

One of the authors Mr. Maruti S. Satpute thanks Dr. Indu Shastri, Research Guide and HOD, National College of Science and Commerce for suggesting a problem and constant valuable guidance throughout the course and providing laboratory facilities.

\section{REFERENCES}

[1]. Martin, K.R.; Appel, C.L. Polyphenols as dietary supplements: A double-edged sword. Nutr. Dietary Suppl. 2010, 2, 1-12.

[2]. Bravo, L. Polyphenols: Chemistry, dietary sources, metabolism, and nutritional significance. Nutr. Rev. 1998, 56, 317-333.

[3]. Harris, C.S.; Mo, F.; Migahed, L.; Chepelev, L.; Haddad, P.S.; Wright, J.S.; Willmore, 
W.G.; Arnason, J.T.; Bennett, S.A.L. Plant phenolics regulate neoplastic cell growth and survival: a quantitative structure-activity and biochemical analysis. Can. J. Physiol. Pharmacol. 2007, 85, 1124-1138.

[4]. Huang, W.Y.; Cai, Y.Z.; Zhang, Y.B. Natural Phenolic Compounds From Medicinal Herbs and Dietary Plants: Potential Use for Cancer Prevention. Nutr. Cancer 2010, 62, 1-20.

[5]. Liu, R.H. Potential synergy of phytochemicals in cancer prevention: Mechanism of action. J. Nutr. 2004, 134, 3479S-3485S.

[6]. Bendini, A.; Cerretani, L.; Carrasco-Pancorbo, A.; Gomez-Caravaca, A.M.; Segura-Carretero, A.; Fernandez-Gutierrez, A.; Lercker, G. Phenolic molecules in virgin olive oils: a survey of their sensory properties, health effects, antioxidant activity and analytical methods. An overview of the last decade. Molecules 2007, 12, 1679-1719.

[7]. Gruz, J.; Ayaz, F.A.; Torun, H.; Strand, M. Phenolic acid content and radical scavenging activity of extracts from medlar (Mespilus germanica L.) fruit at different stages of ripening. Food Chem. 2011, 124, 271-277.

[8]. Ford, C.M.; Hoj, P.B. Multiple glucosyltransferase activities in the grapevine Vitis vinifera L. Aust. J. Grape and Wine Res. 1998, 4, 48-58.

[9]. H.W. Johnston, G.G. Briggs and M. Alexander (1972). "Metabolism of 3chlorobenzoic acid by a pseudomonad". Soil Biology and Biochemistry. 4 (2): 187-190. doi:10.1016/0038-0717(72)90010-7.

[10]. M. S. Satpute, I. Shastri and V. D. Gangan (2018). "Synthesis and Antibacterial activity of novel vanillic acid hybrid derivatives [Part I]'. Rasayan Journal of Chemistry (In Press).

[11]. M. S. Satpute, I. Shastri and V. D. Gangan (2018). "Synthesis and Antibacterial activity of novel vanillic acid hybrid derivatives [Part
II]”. International Journal of Scientific Research in Science and Technology, November-December-2018; 4 (11) : pp. 219223.

[12]. M. S. Satpute, I. Shastri and V. D. Gangan (2018). "Synthesis and Antibacterial activity of novel vanillic acid hybrid derivatives [Part III]". International Journal for Research in Applied Science \& Engineering Technology (IJRASET), Volume 6 Issue XII, Dec 2018, pp. 330-334.

[13]. V. D. Gangan and S. S. Sankhe (2018). "Synthesis and Antimicrobial Activity of Isoeugenol Hybrid Derivatives" International Journal of Scientific Research in Science and Technology, January-2018; 4 (2) : pp. 886 891.

[14]. Mwambete K. D. and Lyombe F. (2011). Antimicrobial activity of medicated soaps commonly used by Dar es Salaam residents in Tanzania. Indian J. Pharm. Sci. 2011, 73 (1), pp. 92 - 98. b ) Al lafi T et. al.. The effect of miswak used in Jordan and Middle East on oral bacteria. International Dental Journal, 1995, 45 (3), pp. 218 - 222. 